\title{
Media as Watchdogs: The Role of News Media in Electoral Competition*
}

\author{
Jimmy Chan ${ }^{\dagger}$ \\ Shanghai University of Finance and Economics
}

Wing Suen ${ }^{\ddagger}$

The University of Hong Kong

June 25,2008

\footnotetext{
${ }^{*}$ We thank Joseph Harrington, the associate editor, the referees, and seminar participants at Johns Hopkins, Northwestern, UCSD, University of Hong Kong, Canadian Economic Theory Conference, the Public Choice Society Meeting, and Econometric Society Winter Meeting for providing valuable comments. The research described in this paper was partially supported by a grant from the Research Grants Council of Hong Kong (Project No. HKU7232/04H). Chan gratefully acknowledges the Hong Kong Institute of Economics and Business Strategy for hospitality while part of this research was conducted.

${ }^{\dagger}$ School of Economics, Shanghai University of Finance and Economics, 777 Guoding Road, Shanghai, China 200433; e-mail: jimmy.hing.chan@gmail.com; Tel: 86-21-65903444; Fax: 86-21-65904198.

${ }^{\ddagger}$ School of Economics and Finance, The University of Hong Kong, Pokfulam, Hong Kong; e-mail: wsuen@econ.hku.hk; Tel: 852-28578505; Fax: 852-25481152.
} 
Abstract. We develop an equilibrium model to analyze the role of the media in electoral competition. When policy payoffs are state-dependent, party policies do not converge to the median voter's ideal policy if the media report only party policies. News analysis about the state, though possibly biased, can discipline off-equilibrium deviations and make the parties adopt more centrist policies. Since voters are rational, the party favored by the media need not win with a higher probability. Instead, media bias may reduce the effectiveness of electoral competition and lead to more polarized policies.

JEL Classification. D72, D82

Keywords. media bias, cheap talk, policy convergence 


\section{Introduction}

In elections voters have little incentive to gather information about complex social issues. Instead they rely on information provided by the news media. Surveys have found that a majority of American voters regularly watch television news and read newspapers, and many of them consider the mass media their principal source of information on public policy and politics.

While relying on the news media allows voters to economize on the cost of information, it also creates an agency problem - the media may influence political outcomes through its agenda setting and framing ability. The charge that American news media are biased is not new. Conservatives have long complained about the "liberal bias" in the mainstream media. More recently, the rising popularity of conservative cable-television and radio news programs and the increasing commercialization of mainstream media have led liberals to question whether the media are becoming dominated by business and conservative interests. The perception of media bias undermines the credibility of the media. An opinion poll reports that in 2004 none of the mainstream media outlets has more than 35 percent of the respondents saying that they can believe all or most of what they see on it (The Pew Center for the People and the Press 2004).

Media bias arises because the media do not merely "report" news. On many social issues political parties offer conflicting theories to justify their own policy proposals. For example, in the recent debate on social security reform, Republicans who favor private accounts argue that private accounts generate higher returns and the current pay-as-you-go system is insolvent, while Democrats dispute these claims and argue that diverting payroll tax to private accounts will worsen the budget deficit. Instead of repeating both sides' arguments, a media outlet may conduct its own investigation to provide an independent assessment. But once a media outlet takes side in policy debates, its views would inevitably be colored by the preference of its editors and journalists.

To avoid the perception of bias, media outlets sometimes try to make news "balanced" and "objective" by giving equal coverage to the views of both sides and refrain from judgments that could be construed as subjective (Fallows 1996). But such a strategy, which presents all policy disagreements as if opinions are evenly divided, may hinder reporting. In a recent article, media critic Michael Massing quotes a reporter of the Los Angeles Times who was frustrated by his editor's effort to make his news story balanced:

"I am completely exasperated by this approach to the news. The 
idea seems to be that we go out to report but when it comes time to write we turn our brains off and repeat the spin from both sides. God forbid we should ... attempt to fairly assess what we see with our own eyes. 'Balanced' is not fair, it's just an easy way of avoiding real reporting and shirking our responsibility to inform readers." 1

At issue is the role of the media in the democratic process. Should they act as watchdogs or passive information providers? In this paper we consider this question and examine the effect of media bias in a Downsian model of electoral competition. We find that media scrutiny, even when potentially biased, can still serve an important social function, making political parties more responsive to the preference of the median voter. It is therefore counter-productive to avoid bias by reporting uncritically.

In our model two political parties compete by choosing policies from a one-dimensional policy space. The policy payoff is a function of a onedimensional state variable that is observed only by the parties and the media but not by voters, who learn about it through the media. The parties do not have the same policy preference as the median voter's. One of them prefers a more left-wing policy while the other prefers a more right-wing one. Hence they may propose policies different from the one preferred by the median voter.

The media report the parties' policies and may also report the state. The latter enables voters to calculate policy payoffs and amounts to the type of independent scrutiny that is the focus of this study. We assume that the media must report party policies truthfully but they may lie about the state in order to promote the policy they prefer. This does not mean that voters are necessarily deceived. Since voters are aware of the media's incentives, they interpret reports about the state rationally. Furthermore, voters may also deduce the state from the parties' policies.

We first consider the case where the media report uncritically. In our model this corresponds to the media reporting only party policies but not the state. We find that in this case in equilibrium the political outcome must deviate from the median voter's ideal policy in some state. The deviation can be large. Within the class of linear equilibria, complete policy

\footnotetext{
${ }^{1}$ The news story in question, published shortly before the 2004 Presidential Election, concerns voter intimidation by the two parties in several swing states. The reporter, based on his own investigation, felt that the Republicans' offense was much more serious than the Democrats', but the editor decided to give equal coverage to the claims of both sides. See Massing (2005).
} 
divergence - each party proposing its own favorite policy - is the only equilibrium outcome. Interestingly, in this equilibrium the median voter actually can infer the state and the best policy for him from the parties' policies; nevertheless neither party has any incentive to respond.

By informing voters of the pros and cons of parties' policies, media scrutiny induces the parties to propose policies that serve the interests of the median voter. In our model, if the media are unbiased, the median voter will always elect the party whose policy is better according to the media. In that case, the model becomes a standard Downsian model, and both parties' policies will converge to the median voter's ideal policy. Uncertainty about bias reduces the influence of the media. Nevertheless, we show that so long as the media are not entirely one-sided, voters will still "trust" the media in the sense that in the event of a policy deviation they are more likely to elect a party when it is supported by the media than when it is not. The incentive to seek media support, therefore, provides a discipline against deviations by the political parties. The result is a greater degree of policy convergence compared to the case where the media report only party policies.

According to the conventional wisdom, the media help the party they favor. That is not necessarily the case in our model. Since voters are aware of the media's objectives, they interpret news strategically. As a result, media bias does not result in biased policies, nor does the party favored by the media always win with higher probability. Nevertheless, media bias is costly because it may cause voters to distrust news. When that happens, both parties have weaker incentives to pursue centrist policies, and party policies becomes more polarized. A solution to this problem is to have more media outlets. When voters have access to news from multiple sources, they can better judge which party's policy serves their interests. We show that two media outlets are better than one, in the sense that they bring about greater policy convergence. Indeed, as the number of independent media outlets becomes sufficiently large, there is full policy convergence even when individual media outlets are biased.

\subsection{Related Literature}

Recently there is growing interest among economists on the issue of media bias. Baron (2006) argues that media bias originates from journalists who distort the news to further their career objectives, and media owners give discretion to journalists in exchange for lower wages. Anderson and McLaren (2007) examine a model where ideological media outlets manipulate the beliefs of news consumers by hiding information. They argue that 
media merger can raise profits but reduce the amount of information transmission. Mullainathan and Shleifer (2005) suggest the media slant news to satisfy biased readers who prefer news that conforms to their existing beliefs. Gentzkow and Shapiro (2006) show how media bias can arise endogenously when Bayesian consumers infer that news reports which conform to their priors are from high quality news sources. Bernhardt et al. (forthcoming) study how the polarization of the electorate can increase news slant and raise the likelihood of electoral mistakes. Other papers that study the policy effects of the media include Stromberg (2004), which argues that public policies tend to favor groups that receive more news coverage from the media, and Besley and Prat (2006), which examines the ability of the government to capture the media and hence to influence political outcomes.

In the papers cited above, the media influence voters' beliefs and their decisions between exogenously-determined alternatives. Our model differs in that the choices faced by the voters are endogenously chosen by political parties. This approach allows us to study how the media affect parties' policy choices, an important issue in its own right. Equally important, it allows us to separate the watchdog role of the media from the reporting role. Since the parties choose different policies in different states, the policies themselves convey information about the underlying state. For example, the public may take a policy of deficit reduction as a sign that the current level of deficit is unsustainable. The greater the number of feasible policies, the more voters can potentially learn from the actual parties' policies. To emphasize the information role of party policies, we assume there are as many policies as states. We show that even in this extreme case knowledge about party policies alone is not sufficient to ensure efficient political outcomes.

Our theoretic model is related to the literature on two-sender information transmission games (Gilligan and Krehbiel 1987, 1989; Krishna and Morgan 2001a, 2001b; Battaglini 2002). While these papers focus on the amount of information that can be revealed when there are two senders, the main goal of our paper is to analyze how the incentives of the two senders (the parties) are affected by the presence of a third (the media). Schultz (1996) examines a model similar to ours except that the state space is countable and voters have no independent information about the state. Martinelli's (2001) model allows voters to have some exogenous private signals. In our paper, we explicitly model voters' private signals as information from possibly biased news analysis.

Throughout, we take the policy preference of the media as given. In a companion paper (Chan and Suen, 2008), we examine how the profit motive affects the positions of the media. In that paper since parties are restricted 
to choose between two feasible policies, the policy response of the parties are much more limited, and voters cannot infer the state from the parties' policies.

\section{The Model}

Two political parties, referred to as parties 1 and 2, compete in a policy space $Y \equiv \Re$. The outcome of a policy $y$ is $y-\theta$, where $\theta$ is a state variable in the space $\Theta \equiv \Re .^{2}$ There is an odd number of voters. Each of them has a utility function

$$
U\left(y, \theta, b_{v}\right)=-\left(y-\theta-b_{v}\right)^{2},
$$

where $b_{v}$ is an individual-specific parameter that denotes the "taste" of the voter.

The state variable $\theta$ represents contextual information that is costly for individual voters to learn. For example, if the policy is about social expenditures, then $\theta$ may include information about the marginal productivity of social spending and the deadweight loss of taxation. Voters know their own tastes but not the state variable $\theta$. The parties, on the other hand, know both $\theta$ and the preferences of the voters. We model both the policy choice and the state variable in one-dimensional space so that the standard Downsian policy-convergence result can serve as a relevant benchmark. Puglisi (2007) explores models of biased communication with multi-dimensional policy issues.

Policy preferences of the two parties are also in the form of (1). Let $b_{i}$ be the taste parameter of party $i$. We normalize the median voter's taste parameter to zero and assume $b_{1}=b>0$ and $b_{2}=-b<0$. Thus, for any $\theta$, the median voter's ideal policy is lower than that of party 1 and higher than that of party 2 . In addition, a party receives a rent $r$ if it is in power. Thus, the total utility of party $i$ is

$$
U\left(y, \theta, b_{i}\right)+I_{i} r,
$$

where $I_{i}=1$ if party $i$ is elected, and $I_{i}=0$ otherwise.

\footnotetext{
${ }^{2}$ The unboundedness of $\Theta$ allows us to focus on perfectly separating equilibria in which voters can infer the equilibrium state from observation of equilibrium policies. Our main argument is not affected by the assumption that the state variable has unbounded support. In the supplementary Web Appendix (available at

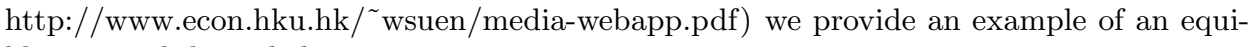
librium with bounded state space.
} 
In the beginning of the game, nature chooses $\theta$ according to some atomless distribution with strictly positive density everywhere. The state $\theta$ is revealed to the parties. Each party $i$ then independently proposes a policy. A strategy of party $i, \sigma_{i}$, is a function that assigns a policy to each $\theta$. Because of the richness of the strategy space, the model has many equilibria. Instead of characterizing all of them, we focus on linear strategies of the form

$$
\sigma_{i}(\theta)=\theta+k_{i},
$$

for some constant $k_{i}$. Section 3 contains further discussion on general nonlinear strategies. Since a linear strategy is characterized by a single parameter, linear equilibria are easy to analyze. The magnitude of the constant gap $k_{1}-k_{2}$ between the parties' policies provides a convenient measure of the efficacy of the electoral process.

We allow for multiple media outlets in Section 5. In the meantime, we assume there is a single media outlet, which we refer to as a "newspaper." The utility function of the newspaper is also in the form of (1), with a taste parameter $b_{m}$. In reality, while parties and voters may know that a media outlet tends to favor a certain type of policies, they may not know its exact policy position on any particular issue. For example, they may know that The New York Times is liberal without knowing its precise stance on school vouchers. Hence, from the perspectives of parties and voters, the newspaper's taste parameter is a random variable $\mathbf{b}_{m}$, which is uniformly distributed on $[-c(1-\tau) / 2, c(1+\tau) / 2]$ with $c>0$ and $\tau \in(-1,1)$. (In what follows, $\mathbf{b}_{m}$ refers to the random variable and $b_{m}$ the realization of that random variable.) Note that the distribution of the newspaper's policy preference has two dimensions. If $c$ is small, it is more likely that the newspaper's policy preference is close to that of the median voter. ${ }^{3}$ The parameter $\tau$ measures the extent of the newspaper's bias. The newspaper tends to favor higher policies when $\tau>0$.

Our assumption that 0 is contained in the support of $\mathbf{b}_{m}$ implies that the newspaper may prefer a higher or lower policy than does the median voter. In other words, though we allow the newspaper to be biased, we assume that it is not completely one-sided. Ansolabehere et al. (2006) collect data on newspaper endorsements in U.S. elections between 1940 and 2002 and find substantial changes in endorsement patterns over time. ${ }^{4}$ Even for House

\footnotetext{
${ }^{3}$ All results apply to the case where the distribution of $\mathbf{b}_{m}$ is not uniform. In general, $1 / c$ corresponds to the density at $b_{m}=0$.

${ }^{4}$ The New York Times, often regarded as a bastion of the liberal press, actually endorsed Republican candidates more often than Democrats in statewide and House races
} 
elections within the same year, 73 percent of the newspapers in their sample endorsed candidates from both the Democratic and the Republican parties when there were more than one race in the state, while only 27 percent of the newspapers endorsed all candidates exclusively from one party. ${ }^{5}$

We treat the newspaper's policy preference as exogenous. In general, there is no reason why the policy preference of the media must coincide with the median voter's. Media outlets controlled by individuals or families may have viewpoints that reflect those of their owners, while those owned by profit-maximizing corporations may adopt the viewpoints of demographic groups targeted by advertisers (Stromberg 2004). Baron (2006) argues that newspaper owners may tolerate biased reporting in exchange for lower wages paid to ideologically-driven journalists. We do not address the question of how competition among media outlets affect their policy preferences.

The role of the newspaper is to inform voters of the parties' policies and the state. Throughout we assume that the newspaper must report party policies truthfully, but it can report the state any way it wants. ${ }^{6}$. Media reports on party policies are mostly based on statements made by the candidates. While a media outlet may quote a candidate selectively, on the whole it has little leeway in the reporting of this kind of information. By contrast, the desirability of a policy often depends on multiple factors. A media outlet can favor a policy by playing up particular news stories, and it is difficult and costly for a reader to judge whether a newspaper covers the "right" stories properly.

Let $M$ denote the set of reports on $\theta$. The newspaper chooses a report $e \in$ $M$ to maximize the probability of election of the party it prefers. Formally, we denote the newspaper's reporting strategy by $\rho$, where $\rho\left(\mathbf{y}, \theta, b_{m}\right) \in M$ is the report of the newspaper with taste parameter $b_{m}$ in state $\theta$ when the party policies are $\mathbf{y}$.

The election takes place after the parties have chosen their policies and the newspaper has sent its report. We assume that the winning party is

during the period 1940-1955. See Table 4 of Ansolabehere et al. (2006) for examples from other newspapers.

${ }^{5}$ If we include all statewide races besides House elections, the percentage of newspapers that endorsed candidates exclusively from one party in any given year reduces to 13 percent. These figures are based on our calculations using the Ansolabehere et al. (2006) data for the sample of newspaper endorsements in 1986-2002.

${ }^{6}$ If news about the state can be credibly communicated to the voters, one would expect the parties themselves would have strong incentives to do so. In that case the role of the media would be limited to reporting passively information that the parties want to send voters. Milgrom and Roberts (1986) show that there is full convergence when the parties can reveal the state credibly. 
committed to carrying out its policy platform after winning the election. ${ }^{7}$ Voters update their beliefs about $\theta$ on the basis of party policies $\mathbf{y}$ and report $e$. Let $\mu(\cdot \mid \mathbf{y}, e)$ denote this posterior belief, and let $\theta_{i}(\mathbf{y}, \sigma)$ denote the states where $\sigma_{i}$ prescribes $y_{i}$ (in the case of linear strategies $(2), \theta_{i}(\mathbf{y}, \sigma)=y_{i}-k_{i}$ ). We require that posterior belief $\mu$ be consistent with parties' strategies $\sigma$ on the equilibrium path. When parties adopt linear strategies, since both $\sigma_{1}$ and $\sigma_{2}$ are one-to-one mappings, the median voter can infer $\theta$ from any $\mathbf{y}$ consistent with $\sigma$.

As is common in signaling games, our model has multiple equilibria, and the parties' equilibrium policies depend critically on the median voter's offequilibrium beliefs, some of which are unreasonable. We limit ourselves to a particular class of off-equilibrium beliefs.

Condition 1 Given $\sigma$, for any $\mathbf{y}$ inconsistent with $\sigma$ and for $e=1,2$,

$$
\mu\left(\theta_{1}(\mathbf{y}, \sigma) \cup \theta_{2}(\mathbf{y}, \sigma) \mid \mathbf{y}, e\right)=1
$$

whenever $\theta_{1}(\mathbf{y}, \sigma) \cup \theta_{2}(\mathbf{y}, \sigma) \neq \emptyset$.

Condition 1 says that whenever possible the median voter believes that only one party has deviated when he observes a pair of policies inconsistent with the parties' equilibrium policies. If the median voter believes that each party deviates independently with a small probability, then he should believe that it is much more likely for one party to deviate than for both to deviate simultaneously. Formally, if the median voter believes that each party $i$ independently deviates from $\sigma_{i}$ to some alternative mixed strategy $\sigma_{i}^{\prime}$ with a small probability $\xi$, then his off-equilibrium beliefs in the limit as $\xi$ tends to zero (holding $\sigma_{i}^{\prime}$ constant) would satisfy Condition $1 .^{8}$

Based on the posterior belief $\mu$, voters cast their ballots for the party that maximizes their expected utilities. The voting strategy of the median voter is denoted by $\pi \equiv\left(\pi^{1}, \pi^{2}\right)$, where $\pi^{1}(\mathbf{y}, e)$ and $\pi^{2}(\mathbf{y}, e)$ are the probabilities (summing to one) of voting for parties 1 and 2, respectively, given the party policies and the newspaper report. Since voter preferences satisfy the singlecrossing condition in $\left(y, b_{v}\right)$, the party chosen by the median voter always receives a majority of votes (Gans and Smart 1996).

The outcome of this game is fully characterized by the strategies of the parties, the newspaper, and the median voter. We analyze the perfect

\footnotetext{
${ }^{7}$ See Alesina (1988) for an analysis of a reputation mechanism for credible commitment.

${ }^{8}$ Condition 1 is stronger than the notion of consistency in Kreps and Wilson (1982), as the latter concept does not require the deviating strategy be held constant as the probability of deviation goes to zero.
} 
Bayesian equilibria of the game, which require that (1) the voting strategy $\pi$ maximizes the median voter's expected utility given posterior belief $\mu$; (2) given $\pi$, the newspaper's endorsement strategy $\rho$ maximizes the election probability of the party it prefers; (3) party strategies $\sigma_{1}$ and $\sigma_{2}$ are best responses to each other given voting strategy $\pi$ and reporting strategy $\rho$; and (4) posterior belief $\mu$ is consistent with party strategy $\sigma$.

\section{Uncritical Reporting}

One school of thought in journalism argues that news media should simply report the views of both sides and avoid making judgments. But while reporting uncritically may minimize bias, it also denies voters an independent source of information about the soundness of a policy. In this section we show that political outcomes cannot be fully efficient when voters learn only the policies $\mathbf{y}$ from the media.

Given voters' utility function (1), a necessary condition for efficiency is that party policies must vary with $\theta$. In Equilibrium 1, electoral competition drives both parties to adopt the ex ante ideal policy (based on prior beliefs $\left.\mu_{0}\right)$ for the median voter. The equilibrium is inefficient because it does not make use of the parties' information about the state.

\section{Equilibrium 1}

Party strategies: $\sigma_{1}=\sigma_{2}=E_{\mu_{0}}[\theta]$ for all $\theta$.

Median voter strategy:

$$
\pi^{1}(\mathbf{y})=\left\{\begin{array}{ccc}
0.5 & \text { if } & \left|y_{1}-E_{\mu_{0}}[\theta]\right|=\left|y_{2}-E_{\mu_{0}}[\theta]\right| \\
1 & \text { if } & \left|y_{1}-E_{\mu_{0}}[\theta]\right|<\left|y_{2}-E_{\mu_{0}}[\theta]\right| \\
0 & \text { if } & \left|y_{1}-E_{\mu_{0}}[\theta]\right|>\left|y_{2}-E_{\mu_{0}}[\theta]\right|
\end{array}\right.
$$

Median voter beliefs: if $y_{1}=y_{2}=E_{\mu_{0}}[\theta]$, then $\mu(\cdot \mid \mathbf{y})=\mu_{0}(\cdot)$; otherwise, $\mu\left(E_{\mu_{0}}[\theta] \mid \mathbf{y}\right)=1$.

There exist equilibria in which parties' policies are strictly increasing in $\theta$. In this case since the median voter can infer the state from the parties' policies, he will always elect the party whose policy is closer to his ideal point. But as the following equilibrium shows, the ability to elect the right party on the equilibrium path does not guarantee that the parties will adopt the median voter's preferred policies. 


\section{Equilibrium 2}

Party strategies: $\sigma_{1}=\theta+b, \sigma_{2}=\theta-b$;

Median voter strategy: $\pi^{1}(\mathbf{y})=0.5$ for all $\mathbf{y} \in Y^{2}$;

Median voter beliefs: if $y_{1}-y_{2} \neq 2 b$, then $\mu\left(\theta_{1}(\mathbf{y}, \sigma) \mid \mathbf{y}\right)=$ $\mu\left(\theta_{2}(\mathbf{y}, \sigma) \mid \mathbf{y}\right)=0.5$; otherwise, $\mu\left(\left(y_{1}+y_{2}\right) / 2 \mid \mathbf{y}\right)=1$.

In equilibrium 2 each party chooses its own favorite policy. The equilibrium policy gap is $2 b$. When the median observes such a policy gap, he concludes that $\theta=\left(y_{1}+y_{2}\right) / 2$ and elects each party with probability 0.5 . When he observes a different, say, narrower, policy gap, he knows one party has deviated to a more moderate policy, but he does not know which. For example, the policy pair $(0.8 b,-b)$ is consistent with either party 1 deviating from $b$ to $0.8 b$ in state $\theta=0$ or party 2 deviating from $-1.2 b$ to $b$ in state $\theta=-0.2$. In the first event the median voter prefers party 1 while in the second event he prefers party 2 . His off-equilibrium belief is that that both events are equally likely, and his voting strategy is again to elect each party with probability 0.5 . Since a party is always elected with probability 0.5 , it is optimal to propose its favorite policy.

Equilibria 1 and 2 illustrate a broader point: In order to achieve efficiency, the parties must make use of its information and choose policies responsive to the state, but doing so weakens electoral competition, leading to policy divergence. This idea is formalized in Proposition 1.

Proposition 1 When the newspaper reports only party policies, in any perfect Bayesian equilibrium where $\sigma_{1}$ and $\sigma_{2}$ are piece-wise continuous and $\mu$ satisfies Condition 1, the equilibrium policies must deviate from the median voter's ideal policy in some states.

The proof of Proposition 1 has two steps. The first shows that under Condition 1 full efficiency can only be achieved if both parties choose the median voter's ideal policy in every state; the second completes the proof by showing that doing so is not self-enforcing. This and all other omitted proofs are presented in the appendix.

To better understand the intuition behind Proposition 1, it is useful to look at the case of linear symmetric equilibria. Consider a strategy profile $\sigma_{1}=\theta+k$ and $\sigma_{2}=\theta-k$. For $\sigma$ to be part of an equilibrium, there must exist some median voter's voting strategy $\pi$ such that, given $\pi$, neither party wants to deviate from its strategy. Suppose $k<b$. Since parties' strategies are more moderate than their favorite policies, there exists some $\varepsilon>0$ such 
that at every state $\theta$ each party $i$ strictly prefers a strategy $\varepsilon$ more partisan than $\sigma_{i}(\theta)$. Specifically, in state $\theta$ party 1 strictly prefers $y_{1}^{\prime}=\theta+k+\varepsilon$ to $y_{1}=\theta+k$, whereas in state $\theta^{\prime}=\theta+\varepsilon$ party 2 strictly prefers $y_{2}^{\prime}=\theta-k$ to $y_{2}=\theta+\varepsilon-k$. Upon observing $\left(y_{1}^{\prime}, y_{2}^{\prime}\right)$ the median voter cannot tell whether it is party 1 deviating in state $\theta$ or party 2 deviating in state $\theta+\varepsilon$. In order to deter party 1 from deviating from $y_{1}$ to $y_{1}^{\prime}$ in state $\theta$, the median voter must elect party 1 with a higher probability when he observes $\left(y_{1}, y_{2}^{\prime}\right)$ than when he observes $\left(y_{1}^{\prime}, y_{2}^{\prime}\right)$. Similarly, in order to deter party 2 from deviating from $y_{2}$ to $y_{2}^{\prime}$ in state $\theta^{\prime}$, he must elect party 2 with a higher probability when he observes $\left(y_{1}^{\prime}, y_{2}\right)$ than when he observes $\left(y_{1}^{\prime}, y_{2}^{\prime}\right)$. Hence,

$$
\pi^{1}(\sigma(\theta))=\pi^{1}\left(y_{1}, y_{2}^{\prime}\right)>\pi^{1}\left(y_{1}^{\prime}, y_{2}^{\prime}\right)>\pi^{1}\left(y_{1}^{\prime}, y_{2}\right)=\pi^{1}\left(\sigma\left(\theta^{\prime}\right)\right) .
$$

That is, party 1's election probability must be lower in state $\theta+\varepsilon$ than in state $\theta$. Moreover the difference in probability must be of the same order of magnitude as $\varepsilon$ since $\lim _{\varepsilon \rightarrow 0}\left(U\left(\sigma_{1}(\theta+\varepsilon), \theta, b\right)-U\left(\sigma_{1}(\theta), \theta, b\right)\right) / \varepsilon>0$. As this argument applies to any $\theta$ and $\theta^{\prime}$ that are $\varepsilon$ apart, we can construct a sequence $\theta^{1}, \theta^{2}, \ldots$ such that for $i \geq 1, \pi^{1}\left(\sigma\left(\theta^{i+1}\right)\right)-\pi^{1}\left(\sigma\left(\theta^{i}\right)\right)$ is positive and bounded away from zero, violating the restriction that $\pi^{1}$ be bounded between 0 and 1 . Hence, $k<b$ cannot be an equilibrium. Using a similar argument we can show that there is no equilibrium with $k>b$. Thus, in all symmetric linear equilibria, $\sigma_{1}=\theta+b$ and $\sigma_{2}=\theta-b$. Since under Condition 1 all linear equilibria must be symmetric, we have the following proposition.

Proposition 2 When the newspaper reports only party policies, in any perfect Bayesian equilibrium where $\mu$ satisfies Condition 1 and $\sigma_{1}$ and $\sigma_{2}$ are linear, the equilibrium policies must be $\sigma_{1}=\theta+b$ and $\sigma_{2}=\theta-b$.

The parties' policies do not converge because, off the equilibrium path, the median voter could not identify which party has deviated to a more partisan policy. Since one of the parties must be elected, at least one would be better off deviating. Note that both this argument and Equilibrium 1 hinges on the median voter's inability to identify the deviating party. Whereas in Equilibrium 1 the inability means that a party deviating to the center will not be rewarded, here it means that a party deviating away from the center will not be punished.

In reality candidates make public statements to promote their policies. Suppose, in addition to choosing a policy, each party chooses a statement from a message set. Both Propositions 1 and 2 continue to hold if the media also report the parties' statements. We only need to modify the 
above argument by making a deviating party also choose the statement it is supposed to make in the state with which the deviating policy is associated. The rest of the argument is the same.

The role of Condition 1 in Propositions 1 and 2 is to ensure that the election is "close" in the sense that the median voter finds the policies of the two parties equally appealing. To see this, suppose that party strategies $\sigma$ are strictly increasing, and that $\left|\sigma_{1}(\theta)-\theta\right|<\left|\sigma_{2}(\theta)-\theta\right|$ for all $\theta$ in some interval $[\underline{\theta}, \bar{\theta}]$. Condition 1 means that for small $\varepsilon$ such that $\left|\sigma_{1}(\theta)+\varepsilon-\theta\right|<$ $\left|\sigma_{2}(\theta)-\theta\right|$ the median voter strictly prefers $\sigma_{1}(\theta)+\varepsilon$ to $\sigma_{2}(\theta)$. As a result party 1 can always gain by deviating a little bit. Proposition 1 would be false without Condition 1. See Krishna and Morgan (2001a, 2001b) for a counter-example.

The logic behind Proposition 2 does not depend on the linearity of the parties' strategies. We can show that in any equilibrium where the parties' strategies are symmetric, strictly increasing, and differentiable, the election probability of party 1 must be strictly decreasing in $\theta$ at a rate uniformly bounded away from zero when

$$
\left|\sigma_{1}(\theta)-\theta\right|=\left|\sigma_{2}(\theta)-\theta\right|<b .
$$

Since election probability is non-negative, this suggests that the parties must be adopting policies arbitrarily close to their respective ideal points in some states.

Proposition 3 When the newspaper reports only party policies, in any perfect Bayesian equilibrium where $\mu$ satisfies Condition 1 and $\sigma_{1}$ and $\sigma_{2}$ are strictly increasing and differentiable, for any $\epsilon>0$ there exists $\theta \in \Theta$ such that

$$
\min \left\{\left|\sigma_{1}(\theta)-\theta\right|,\left|\sigma_{2}(\theta)-\theta\right|\right\}>b-\epsilon
$$

The extent of policy divergence is large in both Equilibria 1 and 2. Although we do not have a lower bound on the equilibrium policy gap for the general case of non-linear strategies, Proposition 3 suggests that it is likely to be substantial in a large class of equilibria.

\section{Media Scrutiny}

In this section we examine the role of media scrutiny in the political process. The analysis is divided into three parts. Subsection 4.1 extends the argument in the last section and derives a necessary condition for policy 
convergence. Subsection 4.2 explains how this can be achieved with the newspaper's report. Finally, subsection 4.3 characterizes the set of symmetric linear equilibria. Since the median voter is indifferent between the symmetric policies proposed in equilibrium, the model does not pin down the equilibrium winning probability $p$ for party $1 .{ }^{9}$ Given any $p$, we determine the maximum degree of policy convergence that can be supported in equilibrium.

\subsection{Necessary Condition for Policy Convergence}

Suppose there exists a symmetric linear equilibrium with policy gap $2 k<2 b$ and in which party 1 is elected with probability $p \in(0,1)$ in all states. Consider any two states $\theta$ and $\theta^{\prime}$, with $\theta^{\prime}-\theta=\varepsilon \in(0, b-k)$. In state $\theta$ party 1's incentive-compatibility constraint requires that it prefers choosing $y_{1}=\theta+k$ to $y_{1}^{\prime}=\theta+k+\varepsilon$. That is,

$$
\begin{aligned}
& p\left(-(b-k)^{2}+r\right)+(1-p)\left((b+k)^{2}\right) \geq \\
& \quad q\left(y_{1}^{\prime}, y_{2}, \theta\right)\left(-(b-k-\varepsilon)^{2}+r\right)+\left(1-q\left(y_{1}^{\prime}, y_{2}, \theta\right)\right)\left(-(b+k)^{2}\right),
\end{aligned}
$$

where $q\left(y_{1}^{\prime}, y_{2}, \theta\right)$ denotes the probability that party 1 wins the election in state $\theta$ when the parties' policies are $\left(y_{1}^{\prime}, y_{2}\right)$. For ease of exposition, we proceed by focusing on equilibria which has the property that that $q\left(\cdot, y_{2}, \theta\right)$ is continuous at $y_{1}^{\prime}=y_{1}$. Subsequently, in the proof of Proposition 4, we establish that all equilibria must indeed have this continuity property.

When $\varepsilon$ is small, the continuity of $q\left(\cdot, y_{2}, \theta\right)$ implies that $q\left(y_{1}^{\prime}, y_{2}, \theta\right)$ is close to $p$. In this case, ignoring the second-order terms of $\varepsilon$, (3) can be written as

$$
2(b-k) \varepsilon p \leq(4 b k+r)\left(p-q\left(y_{1}^{\prime}, y_{2}, \theta\right)\right) .
$$

Note that $2(b-k) \varepsilon$ is the gain from implementing a more partisan policy and $4 b k+r$ is the difference between winning and losing. When party 1 deviates $\varepsilon$ upward, it wins with a more favorable policy, but its winning probability declines by $p-q\left(y_{1}^{\prime}, y_{2}, \theta\right)$.

In state $\theta^{\prime}$ party 2's incentive-compatibility constraint requires that it prefers choosing $y_{2}^{\prime}=\theta^{\prime}-k$ to $y_{2}=\theta^{\prime}-k-\varepsilon$. For small $\varepsilon$, this implies that

$$
2(b-k) \varepsilon(1-p) \leq(4 b k+r)\left(q\left(y_{1}^{\prime}, y_{2}, \theta^{\prime}\right)-p\right) .
$$

\footnotetext{
${ }^{9}$ This probability can be thought of as determined by factors outside the model, such as the degree of party loyalty or voters' perception of the candidates' personal appeal.
} 
Combining (4) and (5) and rearranging the terms, we have

$$
\left(q\left(y_{1}^{\prime}, y_{2}, \theta^{\prime}\right)-q\left(y_{1}^{\prime}, y_{2}, \theta\right)\right) \geq \varepsilon \frac{2(b-k)}{4 b k+r} .
$$

Note that either party 1 deviating upward by $\varepsilon$ in state $\theta$ or party 2 deviating downward by $\varepsilon$ in state $\theta^{\prime}$ results in the same policy pair. Thus, a necessary condition for partial policy convergence is that a party must be elected with lower probability when it is the deviating party, given the same offequilibrium policy pair that produces a wider policy gap. Obviously, this can only happen when voters can identify (probabilistically) the deviating party. When the newspaper reports uncritically, $q\left(y_{1}^{\prime}, y_{2}, \theta\right)$ and $q\left(y_{1}^{\prime}, y_{2}, \theta^{\prime}\right)$ must be equal and, hence, (6) can never be met.

\subsection{Newspaper Strategy}

Since the objective of the newspaper is to maximize the election probability of the party it prefers, in any equilibrium only reports that maximize either party 1's or party 2's election probability will be chosen. We can, therefore, model a report about the state as a binary signal. Henceforth, we assume that $\rho\left(\mathbf{y}, \theta, b_{m}\right) \in\{1,2\}$. Since the labels of the newspaper's reports are arbitrary, for clarity we assume report $i$ leads to a (weakly) higher election probability for party $i$ and refer to it as an endorsement of party $i$. Intuitively, a report that says $\theta>\left(y_{1}+y_{2}\right) / 2$ is tantamount to endorsing the party with the higher policy. ${ }^{10}$

If endorsing a party makes it more likely to be elected, then the newspaper's unique best response is to endorse the party it prefers. Call such a strategy $\rho^{*}$ :

$$
\rho^{*}\left(\mathbf{y}, \theta, b_{m}\right)=1 \quad \text { if and only if } \quad\left|y_{1}-\theta-b_{m}\right| \leq\left|y_{2}-\theta-b_{m}\right| .
$$

Note that the party endorsed by the newspaper may not be the one better for the median voter. In fact, when the newspaper is biased $(\tau \neq 0)$, it may endorse the wrong party with probability greater than 0.5 . Nevertheless, as we show below, newspaper endorsement remains a useful signal.

Define $\beta^{i}(\mathbf{y}, \theta)$ as the ex ante probability that party $i$ will be endorsed by a newspaper using strategy $\rho^{*}$. It is straightforward to show that for

\footnotetext{
${ }^{10}$ Kahn and Kenney (2002) find that newspapers' coverage of senatorial campaigns in the United States is often slanted in favor of the candidates they endorse. Larcinese et al. (2007) show that the coverage of unemployment by U.S. newspapers as a function of the political affiliation of the incumbent president is systematically correlated with their endorsement choices.
} 
$y_{1} \geq \theta \geq y_{2}$,

$$
\beta^{1}(\mathbf{y}, \theta)= \begin{cases}0 & \text { if } \hat{\beta}(\mathbf{y}, \theta)<0 \\ \hat{\beta}(\mathbf{y}, \theta) & \text { if } \hat{\beta}(\mathbf{y}, \theta) \in[0,1] \\ 1 & \text { if } \hat{\beta}(\mathbf{y}, \theta)>1\end{cases}
$$

where

$$
\hat{\beta}(\mathbf{y}, \theta)=\frac{c(1+\tau)+2 \theta-\left(y_{1}+y_{2}\right)}{2 c} .
$$

Suppose the parties adopt symmetric strategies $\sigma_{1}(\theta)=\theta+k$ and $\sigma_{2}(\theta)=$ $\theta-k$ in equilibrium. Upon observing policies $\mathbf{y}^{\prime}$ with a policy gap $\varepsilon$ wider than expected, the median voter cannot tell whether it is party 2 deviating in state $\theta_{1}=\left(y_{1}^{\prime}+y_{2}^{\prime}+\varepsilon\right) / 2$ or party 1 deviating in state $\theta_{2}=\left(y_{1}^{\prime}+y_{2}^{\prime}-\varepsilon\right) / 2$. Using (7), the difference in the probability that party 1 is endorsed under these two possible states (when $\varepsilon$ is small) is

$$
\beta^{1}\left(\mathbf{y}^{\prime}, \theta_{1}\right)-\beta^{1}\left(\mathbf{y}^{\prime}, \theta_{2}\right)=\varepsilon / c>(<) 0 \text { if and only if } \varepsilon>(<) 0 .
$$

Note that party 1 is better for the median voter when $\varepsilon>0$ and party 2 is better when $\varepsilon<0$. Hence, no matter the sign of $\varepsilon$, a party is more likely to be endorsed by a newspaper when it is the better party for the median voter. It then follows from the Bayes' rule that given any belief conditional on an off-equilibrium policy pair $\mathbf{y}^{\prime}$, the median voter should assign a higher probability that a party is the better one when it is endorsed.

\subsection{Equilibrium Policy Gap}

We can now see the connection between policy convergence and newspaper endorsement. Let $\mathbf{y}^{\prime}$ denote the policy pair $(\theta+k, \theta-k-\varepsilon)$. Let $\theta_{1}=\theta$ and $\theta_{2}=\theta-\varepsilon$. The issue for voters is to ascertain whether they are in state $\theta_{1}$ or $\theta_{2}$. By definition, for $i=1,2$, the probability that party 1 wins the election in state $\theta_{i}$ is

$$
q\left(\mathbf{y}^{\prime}, \theta_{i}\right)=\sum_{e=1,2} \beta^{e}\left(\mathbf{y}^{\prime}, \theta_{i}\right) \pi^{i}\left(\mathbf{y}^{\prime}, e\right)
$$

We can write

$$
q\left(\mathbf{y}^{\prime}, \theta_{1}\right)-q\left(\mathbf{y}^{\prime}, \theta_{2}\right)=\left(\beta^{1}\left(\mathbf{y}^{\prime}, \theta_{1}\right)-\beta^{1}\left(\mathbf{y}^{\prime}, \theta_{2}\right)\right)\left(\pi^{1}\left(\mathbf{y}^{\prime}, 1\right)-\pi^{1}\left(\mathbf{y}^{\prime}, 2\right)\right) .
$$

The influence of a newspaper can be measured by $q\left(\mathbf{y}^{\prime}, \theta_{1}\right)-q\left(\mathbf{y}^{\prime}, \theta_{2}\right)$, the change in winning probability for party 1 when there is an off-equilibrium deviation of size $\varepsilon$. Equation (9) shows that a newspaper's influence is 
determined by two factors: first, how likely a small deviation will cause the newspaper to switch its endorsement ("media responsiveness"), and, second, how likely a change in endorsement will change the vote of the median voter ("voter responsiveness").

From equation (8) in the previous subsection, media responsiveness is given by $\beta^{1}\left(\mathbf{y}, \theta_{1}\right)-\beta^{1}\left(\mathbf{y}^{\prime}, \theta_{2}\right)=\varepsilon / c$. Recall that the parameter $1 / c$ stands for the density of newspaper preference at the point $b_{m}=0$. A newspaper is more likely to switch endorsement in response to a policy deviation when $c$ is small.

Turning to voter responsiveness, it is clear from (9) that newspaper endorsement will have the greatest impact if the median voter always votes for the party supported by the newspaper; that is, if $\pi^{1}\left(\mathbf{y}^{\prime}, 1\right)=1$ and $\pi^{1}\left(\mathbf{y}^{\prime}, 2\right)=0$. However, doing so may not be incentive compatible. If an arbitrarily small deviation leads to a discrete change in election probability, then the party which is more likely to win after the deviation will be better off deviating a little bit. In an equilibrium in which party 1 wins with probability $p$, incentive compatibility requires that $\lim _{\varepsilon \rightarrow 0} q\left(\sigma_{1}(\theta)+\varepsilon, \sigma_{2}(\theta), \theta\right)=p$. Since for small $\varepsilon$ the newspaper endorses party 1 with probability approximately equal to $(1+\tau) / 2$, equilibrium requires

$$
\frac{1+\tau}{2} \pi^{1}\left(\mathbf{y}^{\prime}, 1\right)+\frac{1-\tau}{2} \pi^{1}\left(\mathbf{y}^{\prime}, 2\right)
$$

to converge to $p$ as $\varepsilon$ tends to zero. This condition imposes a bound on the extent of voter responsiveness that can be supported in equilibrium. To calculate

$$
\max \pi^{1}\left(\mathbf{y}^{\prime}, 1\right)-\pi^{1}\left(\mathbf{y}^{\prime}, 2\right),
$$

subject to this constraint, the solution involves

$$
\pi^{1}\left(\mathbf{y}^{\prime}, 1\right)=\left\{\begin{array}{l}
\frac{2 p}{1+\tau} \\
1
\end{array} \text { and } \pi^{1}\left(\mathbf{y}^{\prime}, 2\right)=\left\{\begin{array}{ll}
0 & \frac{1+\tau}{2} \geq p \\
\frac{2 p-1-\tau}{1-\tau}
\end{array} \quad \text { when } \frac{1+\tau}{2}<p .\right.\right.
$$

If on the equilibrium path party 1 is more likely to be endorsed than elected (i.e., $(1+\tau) / 2>p)$, then the median voter elects party 2 when it is endorsed and randomizes when party 1 is. On the other hand, if party 1 is less likely to be endorsed than elected, then the median voter elects party 1 when it is endorsed and randomizes when party 2 is. As a result, the maximum voter responsiveness is

$$
\pi^{1}\left(\mathbf{y}^{\prime}, 1\right)-\pi^{1}\left(\mathbf{y}^{\prime}, 2\right)=\min \{2 p /(1+\tau), 2(1-p) /(1-\tau)\} .
$$


Figure 1

Maximum difference between $\pi^{1}\left(\mathbf{y}^{\prime}, 1\right)$ and $\pi^{2}\left(\mathbf{y}^{\prime}, 2\right)$ for various values of $\tau$

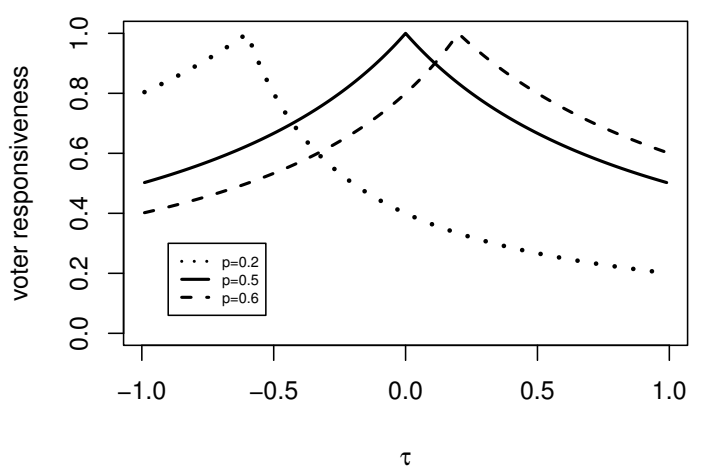

Figure 1 illustrates the value of the maximum voter responsiveness given various values of $p$. Voter responsiveness reaches a maximum of 1 when $\tau=2 p-1$, and it decreases monotonically as $\tau$ deviates away from this value in either direction. One can see that an unbiased newspaper $(\tau=0)$ is not always the most influential. If voters tend to vote for party 2 on the equilibrium path $(p=0.2$, say), then a newspaper is most influential when it is biased for party $2(\tau=-0.6)$.

Substitute (8), (9), and (12) into the incentive compatibility constraint (6), we obtain a necessary condition for a symmetric linear equilibrium with policy gap $2 k$ :

$$
\frac{2(b-k)}{4 b k+r} \leq \frac{1}{c} \min \left\{\frac{2 p}{1+\tau}, \frac{2(1-p)}{1-\tau}\right\} .
$$

The right-hand-side of (13) represents the maximum influence of the newspaper. The left-hand-side, which measures the benefit-cost ratio of a marginal deviation toward a more partisan policy, is decreasing in $k$, since the parties have weaker incentives to deviate when their policies are closer to their respective ideals. Condition (13) thus imposes a lower bound on $k$. We characterize the set of linear symmetric equilibria for the case where the support of the distribution of $\mathbf{b}_{m}$ contains $[-b / 2, b / 2]$.

Proposition 4 Suppose $[-c(1-\tau) / 2, c(1+\tau) / 2] \supset[-b / 2, b / 2]$. Let $k^{*} \equiv$ 
$\max \{0, \hat{k}\}$, where $\hat{k}$ is defined by the equation

$$
\frac{2(b-\hat{k})}{4 b \hat{k}+r}=\frac{1}{c} \min \left\{\frac{2 p}{1+\tau}, \frac{2(1-p)}{1-\tau}\right\} .
$$

Then for any $p \in[0,1]$, the necessary and sufficient condition for the existence of a linear perfect Bayesian equilibrium in which the parties' strategies are $\sigma_{1}=\theta+k$ and $\sigma_{2}=\theta-k$ and party 1 wins with constant probability $p$ is that $k \in\left[k^{*}, b\right]$.

The variable $k^{*}$ denotes the minimum distance between a party's policy and the median voter's ideal point. Since $k^{*}<b$ for any $p \in(0,1)$, Proposition 4 implies that partial policy convergence is always feasible whenever both parties are elected with strictly positive probability. By comparison, $k=b$ is the only linear equilibrium outcome when the newspaper does not report $\theta$. Thus, even when potentially biased, critical reporting can still make the parties more responsive to the interest of the median voter.

Recall that party policies do not converge when the newspaper reports uncritically because the median voter cannot distinguish which party has deviated solely on the basis of party policies. The newspaper endorsement helps solve this problem by allowing the median voter to identify probabilistically the deviating party. At any $k$ that satisfies the constraint (13), there exists voting behavior $\pi$ such that it is not profitable for either party to deviate marginally toward a more partisan policy. The proof of Proposition 4 shows that when the support of the distribution of $\mathbf{b}_{m}$ contains $[-b / 2, b / 2]$, a large deviation is never profitable as well. ${ }^{11}$ Without this condition, our central claim - that partial convergence is possible - remains valid, but the characterization of the equilibrium set becomes more tedious.

Since the median voter is indifferent between the equilibrium policies of the two parties, party 1's election probability $p$ is not pinned down in equilibrium. As a result, the party favored by the newspaper need not be elected with a higher probability than the other party. Note that this result may not hold in an equilibrium in which party policies are not fully revealing. See the discussion in the subsection 4.4.

The effectiveness of the media in promoting policy convergence depends on the degree of media bias. We have shown that media bias should be measured relative to the bias of the electorate. Suppose the newspaper endorses a party with a probability that is higher than the party's equilibrium

\footnotetext{
${ }^{11}$ There does not exist a linear equilibrium in which $k>b$ or $k<0$, for in either case the parties would gain from deviating toward the median voter's ideal point.
} 
winning probability (i.e., $(1+\tau) / 2>p)$. Then, the median voter will vote against its endorsement some of the times. When that happens, both parties have stronger incentives to pursue more partisan policies. Further increases in $\tau$ leads to an increase in $k^{*}$, resulting in more polarized policies. Instead of helping one party at the expense of another, media bias can make everyone - voters and both parties - worse off.

This best equilibrium for the median voter in the class of equilibria described by Proposition 4 is obtained by setting $\tau=2 p-1$ in equation (14), which yields a minimum policy gap of

$$
k^{* *}=\max \left\{0, \frac{2 b c-r}{4 b+2 c}\right\} \text {. }
$$

A greater likelihood that the newspaper shares the same preference as the median voter (decrease in $c$ ), higher office-holding rents (increase in $r$ ), and lower partisan interests (decrease in $b$ ) all allow greater policy convergence (lower $k^{* *}$ ) in the best equilibrium.

\subsection{Robustness}

It is not important for our results that the newspaper observes $\theta$ perfectly. Adding noise to the newspaper's observation would change the endorsement probabilities, but the rest of the analysis would remain essentially the same. The assumption that the two parties observe the same $\theta$ is crucial in keeping the model tractable. If each party observes an independent noisy signal of $\theta$, then conditional on its own signal, each party needs to update its beliefs on the joint distribution of the state and its opponent's policy, and voters need to solve a complicated signal extraction problem on the basis of party policies and newspaper endorsement.

The assumption that the newspaper's report on $\theta$ is pure cheap talk means that its messages are effectively binary in equilibrium. One may argue that news media can do more than endorsing one of the two parties. Suppose there is some positive probability that the newspaper has the ability to reveal credibly a noisy signal of $\theta$. Then in the event of a deviation a newspaper that has the ability to reveal the signal will do so if and only if it favors the party that it prefers. Introducing this change is likely to increase the effectiveness of the newspaper, leading to a greater extent of policy convergence. See Dziuda (2007) for a model along these lines. Our present results emphasize that even without any ability to reveal $\theta$ credibly the newspaper's report can still affect equilibrium policies. 
In reality, parties may modify their policy platforms over the course of a campaign. One way to capture the dynamic effect in our model is to allow parties to change their platforms after learning about the news report. Doing so will allow the parties to learn about the preferences of the newspaper before committing to their final policies.

The central message of this paper is that media scrutiny, even when potentially biased, may help voters to identify the party that has deviated from its equilibrium policy. The idea does not crucially rely on the linearity of the parties' strategies. In Web Appendix A, we present an example to show that the news media play a similar role in an equilibrium in which party strategies are step functions. In a step-function equilibrium, since the equilibrium party policies are not fully revealing, newspaper endorsements affect voting decision both on and off the equilibrium path, and the parties' equilibrium election probabilities are pinned down by the equilibrium conditions. Proposition 4 emphasizes that even when a newspaper has no influence on the equilibrium voting behavior, it may still play a useful watchdog role.

The example in Web Appendix A also shows that the assumption that 0 is in the support of $\mathbf{b}_{m}$, while crucial for the existence of a partially converging linear equilibrium, is not necessary for a newspaper to be influential in a step-function equilibrium. Intuitively, in a step-function equilibrium voters only rely on the newspaper to deter the parties from deviating from one step to another step. Hence, the newspaper endorsement only need to be informative when the party policy gap is one step too wide or more.

In the construction of the linear equilibria in Proposition 4, we assume that 0 is in the interior of the support of $\mathbf{b}_{m}$. The argument survives when the support has 0 as its boundary point, so that the newspaper is known to be biased to one side, but the bias can be arbitrarily small. In that case, $\beta^{1}\left(\mathbf{y}^{\prime}, \theta_{1}\right)-\beta^{1}\left(\mathbf{y}^{\prime}, \theta_{2}\right)$ (the difference in the probability that party 1 is endorsed upon a deviation of size $\varepsilon$ ) is equal to $\varepsilon / 2 c$ instead of $\varepsilon / c$. In Web Appendix B, we show that a linear equilibrium with partial policy convergence can still be supported. If 0 is not the support of $\mathbf{b}_{m}$ at all, symmetric linear strategies with partial policy convergence cannot be an equilibrium.

\section{$5 \quad$ Multiple Newspapers}

In this section we extend our analysis to allow for multiple newspapers. Suppose there are $n$ newspapers, with taste parameters $\mathbf{b}_{j}(j=1, \ldots, n)$. Let $\mathbf{b}_{j}$ be uniformly distributed on $\left[-c\left(1-\tau_{j}\right) / 2, c\left(1+\tau_{j}\right) / 2\right]$, with $\tau_{j} \in$ 
$(-1,+1)$. We assume that voters know the endorsements of all newspapers. Let $\mathbf{e} \equiv\left(e_{1}, \ldots, e_{n}\right) \in\{1,2\}^{n}$ denote an endorsement profile, where $e_{j}$ is the party endorsed by newspaper $j$. A voting strategy of the median voter can be denoted by $\pi^{1}(\mathbf{y}, \mathbf{e})$. Since voters have the same information, the electoral outcome is determined by the vote of the median voter. The probability that party 1 is elected in state $\theta$ when the policy profile is $\mathbf{y}$ is

$$
q(\mathbf{y}, \theta)=\sum_{\mathbf{e}} \beta^{\mathbf{e}}(\mathbf{y}, \theta) \pi^{1}(\mathbf{y}, \mathbf{e})
$$

where $\beta^{\mathbf{e}}(\mathbf{y}, \theta)$ is the ex ante probability of observing endorsement profile $\mathbf{e}$.

Many results developed in the previous section can be readily applied to the current situation. Suppose in equilibrium party 1 is elected with probability $p$. Then, the maximum influence of the media is given by finding a probability $\pi^{1}(\mathbf{y}, \mathbf{e})$ for each $\mathbf{e} \in\{1,2\}^{n}$ that solves

$$
\begin{aligned}
& M I \equiv \max 2 \sum_{\mathbf{e}} \frac{\partial \beta^{\mathbf{e}}(\sigma(\theta), \theta)}{\partial y_{2}} \pi^{1}(\mathbf{y}, \mathbf{e}) \\
& \text { subject to } \sum_{\mathbf{e}} \beta^{\mathbf{e}}(\mathbf{y}, \theta) \pi^{1}(\mathbf{y}, \mathbf{e})=p .
\end{aligned}
$$

( $M I$ is constant for all $\theta$.) Following the logic of Proposition 4, the minimum equilibrium policy gap is equal to $2 k^{*}=\max \{0,2 \hat{k}\}$ where $\hat{k}$ is defined by the equation

$$
\frac{2(b-\hat{k})}{4 b \hat{k}+r}=M I .
$$

To determine $k^{*}$, we simply have to express $M I$ as a function of the characteristics of the media. A higher media influence leads to a smaller equilibrium policy gap. We illustrate the calculations with two examples. In the first example, there are two newspapers with preferences that are perfectly correlated. In the second example, there are a large number of newspapers with preferences that are independent and identically distributed.

In the case of perfectly correlated preferences with two newspapers $A$ and $B$, there is a constant gap between the ideal policies of the two newspapers. We can let $\mathbf{b}_{B}=\mathbf{b}_{A}-c\left(\tau_{A}-\tau_{B}\right)$. Without loss of generality, assume that $\tau_{A} \geq \tau_{B}$. Then newspaper $A$ endorses party 1 whenever newspaper $B$ does. There are only three possible endorsement profiles: $(1,1),(1,2)$, and $(2,2)$.

The characterization of equilibria in this example is given in Web Appendix C. As in the case of a single newspaper, the influence of the media depends on the magnitude of $\tau_{A}$ and $\tau_{B}$ relative to the equilibrium behavior 
of the median voter. Suppose the median voter elects party 1 with probability $p$ in equilibrium. If $\tau_{A} \geq \tau_{B}>2 p-1$, then the probability of the endorsement profile $(1,1)$ is greater than $p$ on the equilibrium path, while the combined probability of $(1,2)$ and $(2,2)$ is less than $p$. For small deviations, to satisfy the constraint that $q(\mathbf{y}, \theta)=p$, the median voter treats $(1,1)$ as a neutral signal (meaning that he votes for both parties with positive probability) and treats both $(1,2)$ and $(2,2)$ as signals against party 1 (meaning that he votes for party 1 with probability zero). In other words, the median voter chooses party 1 with positive probability if and only if newspaper $B$ endorses party 1 . The minimum equilibrium policy gap is therefore identical to that when there is a single newspaper with a bias equal to $\tau_{B}$. Similar reasoning establishes that when $2 p-1>\tau_{A} \geq \tau_{B}$, the minimum policy gap with two newspapers is the same as the minimum policy gap when there is a single newspaper with a bias $\tau_{A}$. In either case, when the two newspapers are biased in the same direction relative to the median voter, it is the less extreme newspaper that determines equilibrium policy outcomes.

In the case when the newspapers are biased in opposite directions relative to the median voter, we have $\tau_{A} \geq 2 p-1 \geq \tau_{B}$. Now on the equilibrium path the probability of $(1,1)$ is less than $p$ and the probability of $(2,2)$ is less than $1-p$. For small deviations the median voter treats $(1,1)$ as a signal in favor of party 1 (i.e., $\left.\pi^{1}(\mathbf{y},(1,1))=1\right),(2,2)$ as one in favor of party 2 (i.e., $\left.\pi^{1}(\mathbf{y},(2,2))=0\right)$, and $(1,2)$ as one that is neutral. A maximum influence of the media in this case is given by

$$
M I=2\left(\frac{1}{2 c}\right)\left(\pi^{1}(\mathbf{y},(1,1))-\pi^{1}(\mathbf{y},(2,2))\right)=\frac{1}{c} .
$$

This is the same as the case of a single newspaper with a bias $\tau=2 p-1$. In this case, the best equilibrium policy gap $k^{* *}$ can be supported.

Two lessons can be drawn from this example. First, the presence of multiple media outlets encourages political parties to adopt policies that more closely reflect the policy preference of the median voter. Regardless of whether the two newspapers have the same bias or opposite biases relative to the median voter, we have

$$
M I\left(\tau_{A}, \tau_{B}\right) \geq \max \left\{M I\left(\tau_{A}\right), M I\left(\tau_{B}\right)\right\} .
$$

Second, the extent of media bias cannot be assessed by examining the bias of each individual media outlet in isolation. The influence of one newspaper depends on the bias of the other newspaper. It is the ecology of the media rather than the biases of individual outlets that determines their role in 
the political process. These lessons are further illustrated by our second example.

In our second example, the mass media are made up of $n$ independent newspapers with identical bias $\tau$. As all newspapers are identical, the posterior belief of the median voter depends only on the number of endorsements each party receives. Let $x$ be the number of newspapers that endorse party 1. In equilibrium $x$ follows a binomial distribution,

$$
f(n, x) \equiv\left(\begin{array}{l}
n \\
x
\end{array}\right) \hat{\tau}^{x}(1-\hat{\tau})^{n-x}
$$

where $\hat{\tau}=(1+\tau) / 2$.

Let $x^{*}$ be the $p$-th quantile of $x$. Then $x=x^{*}$ is the neutral signal. The median voter votes for party 1 with probability one if $x \geq x^{*}+1$ and he votes for party 1 with probability zero if $x \leq x^{*}-1$. Thus, any individual newspaper can influence the electoral outcome if and only if there are exactly $x^{*}-1$ or $x^{*}$ other newspapers that endorses party 1 . The influence of the media as a group is just $n$ times of the influence of an individual newspaper. The influence of an individual newspaper goes to 0 at the rate $1 / \sqrt{n}$ as $n$ approaches infinity. Hence, regardless of the magnitude of the bias $\tau$, the influence of the media as a group grows at the rate $\sqrt{n}$. We have the following result.

Proposition 5 Suppose all news media outlets are identical and independent, and that the support of $\mathbf{b}_{j}$ contains $[-b, b]$. Then as the number of media outlets tends to infinity, the minimum equilibrium policy gap that is consistent with party 1 being elected with probability $p$ tends to zero.

\section{Conclusion}

We provide an analysis of the role of the media in the political process. In an environment in which voters have little incentive to collect information about public policies, the media offer two types of news that help inform voters' decisions. The first type is direct reporting of the policies proposed by political parties. There is relatively little distortion and manipulation of this type of hard news in modern media. The second type of news ranges from analysis of news background to critical commentary on public policies to endorsement of campaign candidates. This type of news is difficult to verify and is therefore subject to manipulation when media outlets have their own policy preferences. Paradoxically, we find that electoral competition is ineffective when the media only provide the first type of news. 
In this context, critical news analysis provided by the media, even though it may be unverifiable and tainted with bias, can serve a useful social function. We show that competition for positive news analysis provides an incentive for political parties to pursue more centrist policies. This role of the media, however, is quite subtle and may be difficult to detect empirically, because in the model news analysis only works by altering off-equilibrium voting behavior. Our model only determines a set of equilibrium policy choices, but it does not pin down the equilibrium probability of winning for each political party. So, observing the relationship between the frequency of media endorsement and the frequency of electoral success may not adequately capture the influence of the media on the political process.

We also find that the common notion of "media bias" has to be examined carefully. Since voters interpret news rationally in our model, the party favored by the media need not be elected with a higher probability. Moreover, the bias of the media should be measured relative to the behavior of the median voter. When there is a single media outlet, the most effective news outlet is one with a bias similar to that of the median voter (i.e., it endorses a certain party with the same frequency as the median voter elects that party), for then the median voter's voting choice can be most responsive to the news analysis offered by that news outlet. Even when media bias is harmful, it does not bias party policies in a systematic direction. Instead, the detrimental effect of media bias is manifested through greater policy polarization, which hurts the interests of all voters. The notion of media bias is even more complex when there are multiple media outlets, since it is the ecology of the media rather than the biases of individual media outlets that determine policy outcomes. Generally, one way to induce more centrist policies is to ensure that the media contain multiple independent voices. As the number of independent media outlets becomes arbitrarily large, there exists an equilibrium with full policy convergence. 


\section{Appendix}

\section{Proof of Proposition 1}

Suppose, by way of contradiction, there exists an equilibrium $\sigma^{*}$ such that (1) for all $\theta$ either $\sigma_{1}^{*}(\theta)$ or $\sigma_{2}^{*}(\theta)$ is equal to $\theta$; and (2) there exists some $i$ and $\theta^{\prime}$ such that $\sigma_{i}^{*}\left(\theta^{\prime}\right) \neq \theta^{\prime}$ (with $i=2$, say). Since $\sigma_{2}^{*}$ is piece-wise continuous, there exists $\theta^{\prime \prime}$ near $\theta^{\prime}$ and $\varepsilon>0$ such that $\sigma_{2}^{*}(\theta) \neq \theta$ for all $\theta \in\left(\theta^{\prime \prime}-\varepsilon, \theta^{\prime \prime}+\varepsilon\right)$; it follows that $\sigma_{1}^{*}(\theta)=\theta$ for all $\theta \in\left(\theta^{\prime \prime}-\varepsilon, \theta^{\prime \prime}+\varepsilon\right)$. Select $\widetilde{\theta} \in\left(\theta^{\prime \prime}, \theta^{\prime \prime}+\varepsilon\right)$ such that in state $\theta^{\prime \prime}$ party 1 strictly prefers $\sigma_{1}^{*}(\widetilde{\theta})$ to $\sigma_{1}^{*}\left(\theta^{\prime \prime}\right)$ and the median voter strictly prefer $\sigma_{1}^{*}(\widetilde{\theta})$ to $\sigma_{2}^{*}\left(\theta^{\prime \prime}\right)$. By Condition 1 , upon observing $\mathbf{y} \equiv\left(\sigma_{1}^{*}(\widetilde{\theta}), \sigma_{2}^{*}\left(\theta^{\prime \prime}\right)\right)$, the median voter must believe that the true state is either $\theta^{\prime \prime}$ or $\tilde{\theta}$. Since the median voter, by construction, strictly prefers $\sigma_{1}^{*}(\widetilde{\theta})$ to $\sigma_{2}^{*}\left(\theta^{\prime \prime}\right)$ in either $\theta^{\prime \prime}$ or $\widetilde{\theta}$, he must elect party 1 when

he observes $\mathbf{y}$. Party 1 therefore will be better off choosing $\sigma_{1}^{*}(\widetilde{\theta})$ in state $\theta^{\prime \prime}$, contradicting the supposition that $\sigma^{*}$ is an equilibrium. Hence, if in equilibrium at least one party chooses $\theta$ in each $\theta$, then it must be that both parties choose $\theta$ in all $\theta$. But by Proposition $2, \sigma_{1}(\theta)=\sigma_{2}(\theta)=\theta$ cannot be part of an equilibrium.

\section{Proof of Proposition 3}

Suppose $\sigma_{1}$ and $\sigma_{2}$ are strictly increasing and differentiable, and there exists $\varepsilon>0$ such that, for all $\theta \in \Theta$,

$$
\theta-b+\varepsilon<\sigma_{2}(\theta) \leq \sigma_{1}(\theta)<b+\theta-\varepsilon .
$$

Let

$$
\tilde{\pi}^{1}\left(\theta_{1}, \theta_{2}\right) \equiv \pi^{1}\left(\sigma\left(\theta_{1}\right), \sigma\left(\theta_{2}\right)\right)
$$

denote party 1's election probability under policy platforms $\sigma_{1}\left(\theta_{1}\right)$ and $\sigma_{2}\left(\theta_{2}\right)$, and let $p(\theta) \equiv \tilde{\pi}^{1}(\theta, \theta)$ denote party 1's equilibrium election probability.

For any $\theta, \theta^{\prime} \in \Theta$, incentive compatibility requires that party 1 prefers $\sigma_{1}(\theta)$ to $\sigma_{1}\left(\theta^{\prime}\right)$ in $\theta$, while party 2 prefers $\sigma_{2}\left(\theta^{\prime}\right)$ to $\sigma_{2}(\theta)$ in $\theta^{\prime}$. Hence,

$$
\begin{aligned}
& p(\theta)\left(U_{1}\left(\sigma_{1}(\theta), \theta\right)+r\right)+(1-p(\theta)) U_{1}\left(\sigma_{2}(\theta), \theta\right) \\
& \geq \tilde{\pi}^{1}\left(\theta^{\prime}, \theta\right)\left(U_{1}\left(\sigma_{1}\left(\theta^{\prime}\right), \theta\right)+r\right)+\left(1-\tilde{\pi}^{1}\left(\theta^{\prime}, \theta\right)\right) U_{1}\left(\sigma_{2}(\theta), \theta\right),
\end{aligned}
$$

and

$$
\begin{aligned}
& \left(1-p\left(\theta^{\prime}\right)\right)\left(U_{2}\left(\sigma_{2}\left(\theta^{\prime}\right), \theta^{\prime}\right)+r\right)+p\left(\theta^{\prime}\right) U_{2}\left(\sigma_{1}\left(\theta^{\prime}\right), \theta^{\prime}\right) \\
& \geq\left(1-\tilde{\pi}^{1}\left(\theta^{\prime}, \theta\right)\right)\left(U_{2}\left(\sigma_{2}(\theta), \theta^{\prime}\right)+r\right)+\tilde{\pi}^{1}\left(\theta^{\prime}, \theta\right) U_{2}\left(\sigma_{1}\left(\theta^{\prime}\right), \theta^{\prime}\right),
\end{aligned}
$$


Define, for $i \in\{1,2\}$ and $j \neq i$,

$$
D_{i}\left(\theta_{i}, \theta\right) \equiv U_{i}\left(\sigma_{i}\left(\theta_{i}\right), \theta\right)-U_{i}\left(\sigma_{j}(\theta), \theta\right)+r
$$

as the difference in payoff for party $i$ between winning with platform $\sigma_{i}\left(\theta_{i}\right)$ and losing to platform $\sigma_{j}(\theta)$ in state $\theta$. Since $D_{i}(\theta, \theta)>0$ for all $\theta$ by supposition, equations (18) and (19) can be written as

$$
p(\theta) \frac{D_{1}(\theta, \theta)}{D_{1}\left(\theta^{\prime}, \theta\right)} \geq \tilde{\pi}^{1}\left(\theta^{\prime}, \theta\right)
$$

and

$$
\left(1-p\left(\theta^{\prime}\right)\right) \frac{D_{2}\left(\theta^{\prime}, \theta^{\prime}\right)}{D_{2}\left(\theta, \theta^{\prime}\right)} \geq 1-\tilde{\pi}^{1}\left(\theta^{\prime}, \theta\right)
$$

Combining equations (20) and (21) gives

$$
p(\theta) \frac{D_{1}(\theta, \theta)}{D_{1}\left(\theta^{\prime}, \theta\right)} \geq 1-\left(1-p\left(\theta^{\prime}\right)\right) \frac{D_{2}\left(\theta^{\prime}, \theta^{\prime}\right)}{D_{2}\left(\theta, \theta^{\prime}\right)} .
$$

Rearranging terms, we have

$$
p(\theta)-p\left(\theta^{\prime}\right) \geq p(\theta)\left(1-\frac{D_{1}(\theta, \theta)}{D_{1}\left(\theta^{\prime}, \theta\right)}\right)+\left(1-p\left(\theta^{\prime}\right)\right)\left(1-\frac{D_{2}\left(\theta^{\prime}, \theta^{\prime}\right)}{D_{2}\left(\theta, \theta^{\prime}\right)}\right) .
$$

Since the $\theta$ and $\theta^{\prime}$ are arbitrary, we can interchange $\theta$ and $\theta^{\prime}$ and obtain

$$
p(\theta)-p\left(\theta^{\prime}\right) \leq p\left(\theta^{\prime}\right)\left(\frac{D_{1}\left(\theta^{\prime}, \theta^{\prime}\right)}{D_{1}\left(\theta, \theta^{\prime}\right)}-1\right)+(1-p(\theta))\left(\frac{D_{2}(\theta, \theta)}{D_{2}\left(\theta^{\prime}, \theta\right)}-1\right) .
$$

Divide equations (22) and (23) by $\theta-\theta^{\prime}$, the terms on the right-hand side of (22) and (23) both converge to

$$
p(\theta) \frac{d \sigma_{1}(\theta)}{d \theta} \frac{2\left(\sigma_{1}(\theta)-\theta-b\right)}{D_{1}(\theta, \theta)}+(1-p(\theta)) \frac{d \sigma_{2}(\theta)}{d \theta} \frac{2\left(\theta-\sigma_{2}(\theta)-b\right)}{D_{2}(\theta, \theta)}
$$

as $\theta^{\prime}$ tends to $\theta$. It follows that $p$ is differentiable and its derivative equals the above expression. Note that by supposition, both $D_{1}(\theta, \theta)$ and $D_{2}(\theta, \theta)$ are positive and less than $4 b^{2}$, and both $\left(b+\theta-\sigma_{1}(\theta)\right)$ and $\left(b-\theta+\sigma_{2}(\theta)\right)$ are positive and greater than $\varepsilon$. Hence,

$$
\frac{d p}{d \theta}<-\frac{\varepsilon}{2 b^{2}}\left(p(\theta) \frac{d \sigma_{1}(\theta)}{d \theta}+(1-p(\theta)) \frac{d \sigma_{2}(\theta)}{d \theta}\right)<0 .
$$

Since $\sigma_{1}$ and $\sigma_{2}$ satisfy (17), they increase without bound. Thus, $p$ must become negative at some point, a contradiction. 


\section{Proof of Proposition 4}

Since the parties' election probabilities are constant, it is more convenient to express the incentive compatibility constraints in terms of the difference between the actual policy gap and the equilibrium policy gap. Suppose the parties adopt equilibrium policies $\sigma_{1}=\theta+k$ and $\sigma_{2}=\theta-k$. In any $\theta$ the probability that the newspaper endorses party 1 when party $j=1,2$ deviates away from the median voter's ideal policy by $\varepsilon$ is

$$
\beta^{1 *}(\varepsilon, j)= \begin{cases}0 & \text { if } \hat{\beta}^{*}(\varepsilon, j)<0, \\ \hat{\beta}^{*}(\varepsilon, j) & \text { if } \hat{\beta}^{*}(\varepsilon, j) \in[0,1], \\ 1 & \text { if } \hat{\beta}^{*}(\varepsilon, j)>1\end{cases}
$$

where

$$
\hat{\beta}^{*}(\varepsilon, j)=\frac{c(1+\tau)+(-1)^{j} \varepsilon}{2 c} .
$$

For any $\mathbf{y}$, define $\varepsilon \equiv y_{1}-y_{2}-2 k$. Note that $\mathbf{y}$ can be reached by either party 1 deviating by $\varepsilon$ upward in state $\theta_{2}(\mathbf{y}, \sigma)$ or by party 2 deviating by $\varepsilon$ downward in state $\theta_{1}(\mathbf{y}, \sigma)$. Party 1's election probability when it is party $j$ which has deviated is

$$
q^{*}(\varepsilon, j)=\sum_{e=1,2} \beta^{e *}(\varepsilon, j) \pi^{1 *}(\varepsilon, e)
$$

where $\pi^{1 *}(\varepsilon, e)$ denote the probability that the median voter elects party $i$ when he observes $\mathbf{y}$ and the newspaper endorses party $e$. Incentive compatibility requires that party 1 prefers the equilibrium policy than deviating upward by $\varepsilon$ in $\theta_{2}(\mathbf{y}, \sigma)$ :

$$
\begin{aligned}
& p\left(-(b-k)^{2}+r\right)+(1-p)\left(-(b+k)^{2}\right) \\
& \geq q^{*}(\varepsilon, 1)\left(-(b-\varepsilon-k)^{2}+r\right)+\left(1-q^{*}(\varepsilon, 1)\right)\left(-(b+k)^{2}\right) .
\end{aligned}
$$

Similarly, Party 2 prefers the equilibrium policy to deviating $\varepsilon$ downward in $\theta_{1}(\mathbf{y}, \sigma)$ :

$$
\begin{aligned}
& (1-p)\left(-(b-k)^{2}+r\right)+p\left(-(b+k)^{2}\right) \\
& \geq\left(1-q^{*}(\varepsilon, 2)\right)\left(-(b-\varepsilon-k)^{2}+r\right)+q^{*}(\varepsilon, 2)\left(-(b+k)^{2}\right) .
\end{aligned}
$$

For small $\varepsilon \in(-(1-|\tau|) c,(1+|\tau|) c)$ and $\beta^{1 *}(\varepsilon, j) \in(0,1)$, the constraints (24) and (25) can by combined into

$$
\begin{aligned}
& 1-\left[1-\left(\frac{1-\tau}{2}-\frac{\varepsilon}{2 c}\right) \pi^{1 *}(\varepsilon, 2)-\left(\frac{1+\tau}{2}+\frac{\varepsilon}{2 c}\right) \pi^{1 *}(\varepsilon, 1)\right] w(k, \varepsilon) \\
& \geq p \geq\left[\left(\frac{1+\tau}{2}-\frac{\varepsilon}{2 c}\right) \pi^{1 *}(\varepsilon, 1)+\left(\frac{1-\tau}{2}+\frac{\varepsilon}{2 c}\right) \pi^{1 *}(\varepsilon, 2)\right] w(k, \varepsilon),
\end{aligned}
$$


where

$$
w(k, \varepsilon) \equiv\left(1+\frac{2(b-k) \varepsilon-\varepsilon^{2}}{4 b k+r}\right) .
$$

Taking limits on both sides, we have

$$
\begin{aligned}
\frac{1+\tau}{2} \lim _{\varepsilon \rightarrow 0} \inf \pi^{1 *}(\varepsilon, 1) & +\frac{1-\tau}{2} \lim _{\varepsilon \rightarrow 0} \inf \pi^{1 *}(\varepsilon, 2) \\
\geq & \geq \frac{1+\tau}{2} \lim _{\varepsilon \rightarrow 0} \sup \pi^{1 *}(\varepsilon, 1)+\frac{1-\tau}{2} \lim _{\varepsilon \rightarrow 0} \sup \pi^{1 *}(\varepsilon, 2),
\end{aligned}
$$

which implies that

$$
\frac{1+\tau}{2} \lim _{\varepsilon \rightarrow 0} \pi^{1 *}(\varepsilon, 1)+\frac{1-\tau}{2} \lim _{\varepsilon \rightarrow 0} \pi^{1 *}(\varepsilon, 2)=p .
$$

Equation (27) requires a party's election probability be continuous in its own policy at $\varepsilon=0$.

Focus on the first and the last terms of (26). Expanding and canceling like terms, we have

$$
\begin{gathered}
\left(-1+\frac{(1+\tau) \pi^{1 *}(\varepsilon, 1)}{2}+\frac{(1-\tau) \pi^{1 *}(\varepsilon, 2)}{2}\right) \frac{2(b-k) \varepsilon}{4 b k+r}+\zeta \geq \\
\left(\frac{(1+\tau) \pi^{1 *}(\varepsilon, 1)}{2}+\frac{(1-\tau) \pi^{1 *}(\varepsilon, 2)}{2}\right) \frac{2(b-k) \varepsilon}{4 b k+r}-\frac{\varepsilon}{c}\left(\pi^{1 *}(\varepsilon, 1)-\pi^{1 *}(\varepsilon, 2)\right),
\end{gathered}
$$

where $\zeta$ contains second or higher order terms of $\varepsilon$. Dividing both sides of this equation by $\varepsilon>0$, and then taking limits, we have

$$
p \frac{2(b-k)}{4 b k+r}+(1-p) \frac{2(b-k)}{4 b k+r} \leq \frac{1}{c} \lim _{\varepsilon \rightarrow 0}\left(\pi^{1 *}(\varepsilon, 1)-\pi^{1 *}(\varepsilon, 2)\right) .
$$

Equation (28) imposes an lower-bound on $k$ as the left-hand-side of (28) is decreasing in $k$. To minimize the lower-bound on $k$, we need to maximize the right-hand side of (28) subject to the constraint of (27). Since both the objective function and the constraint are linear, the maximum is attained when either $\lim _{\varepsilon \rightarrow 0} \pi^{1 *}(\varepsilon, 1)=1$ or $\lim _{\varepsilon \rightarrow 0} \pi^{1 *}(\varepsilon, 2)=0$. Specifically, $\lim _{\varepsilon \rightarrow 0}\left(\pi^{1 *}(\varepsilon, 1)-\pi^{1 *}(\varepsilon, 2)\right)$ is maximized when

$\lim _{\varepsilon \rightarrow 0} \pi^{1 *}(\varepsilon, 1)=\left\{\begin{array}{l}\frac{2 p}{1+\tau} \\ 1\end{array}\right.$ and $\lim _{\varepsilon \rightarrow 0} \pi^{1 *}(\varepsilon, 2)=\left\{\begin{array}{ll}0 & \tau \geq 2 p-1, \\ \frac{2 p-1-\tau}{1-\tau}\end{array}\right.$ when $\begin{array}{l}\tau<2 p-1 .\end{array}$

Substituting this into (28) yields (14). 
We have already shown in text that $\rho^{*}$ is a best response for the newspaper and that any $\pi^{i *}(\varepsilon, e) \in[0,1]$ can be rationalized. Hence, we need only to show that for all $\varepsilon$ there exists $\pi^{i *}(\varepsilon, j) \in[0,1], i, j \in\{1,2\}$, such that (24) and (25) hold.

For all $k \in\left[k^{*}, b\right]$, each party's policy is more moderate than its ideal policy. For all $\varepsilon<0,(24)$ and $(25)$ are satisfied by setting $\pi^{1 *}(\varepsilon, 1)=$ $\pi^{1 *}(\varepsilon, 2)=p$. Suppose (24) and (25) are satisfied for $\varepsilon=b-k$ by some $\pi^{1 *}(b-k, 1)$ and $\pi^{1 *}(b-k, 2)$. Then for all $\varepsilon>b-k,(24)$ and (25) will be satisfied by setting $\pi^{1 *}(\varepsilon, 1)=\pi^{1 *}(b-k, 1)$ and $\pi^{1 *}(\varepsilon, 2)=\pi^{1 *}(b-k, 2)$.

To complete the proof, we still need to show that (24) and (25) can be met by some $\pi^{1 *}(\varepsilon, 1)$ and $\pi^{1 *}(\varepsilon, 2)$ for $\varepsilon \in(0, b-k]$. We do this in two parts. Note that $w(\varepsilon, k)>1$ for $\varepsilon \in(0, b-k]$.

Case (i): $p \leq\left(\frac{1+\tau}{2}-\frac{\varepsilon}{2 c}\right) w(\varepsilon, k)$.

Set $\pi^{1 *}(\varepsilon, 2)=0$ for all $\varepsilon$. Then (24) and (25) become

$$
\frac{p}{\left(\frac{1+\tau}{2}-\frac{\varepsilon}{2 c}\right) w(\varepsilon, k)} \geq \pi^{1 *}(\varepsilon, 1) \geq \frac{p+w(\varepsilon, k)-1}{\left(\frac{1+\tau}{2}+\frac{\varepsilon}{2 c}\right) w(\varepsilon, k)} .
$$

For all $k \geq k^{*}(p)$ and for all $\varepsilon \in(0, b-k]$, the difference between the left-hand-side and the right-hand-side of (29) has the same sign as

$$
\frac{(1+\tau) \varepsilon}{2}\left(\frac{2 p}{c(1+\tau)}-\frac{2(b-k)}{4 b k+r}\right)+\frac{\varepsilon}{2 c}(w(\varepsilon, k)-1)+\frac{1+\tau}{2} \frac{\varepsilon^{2}}{4 b k+r},
$$

which is positive. Thus the left-hand-side of $(29)$ is greater than the righthand-side. Since by supposition $p \leq\left(\frac{1+\tau}{2}-\frac{\varepsilon}{2 c}\right) w(\varepsilon, k)$, the left-hand side of (29) is between 0 and 1 . Hence, for all $k \geq k^{*}(p)$ and for all $\varepsilon \in(0, b-k]$, there exists $\pi^{1 *}(\varepsilon, 1) \in[0,1]$ that satisfies $(29)$.

Case (ii): $p>\left(\frac{1+\tau}{2}-\frac{\varepsilon}{2 c}\right) w(\varepsilon, k)$.

Set $\pi^{1 *}(\varepsilon, 1)=1$ for all $\varepsilon$. Then (24) and (25) become

$$
\frac{p}{\left(\frac{1-\tau}{2}+\frac{\varepsilon}{2 c}\right) w(\varepsilon, k)}-\frac{\frac{1+\tau}{2}-\frac{\varepsilon}{2 c}}{\frac{1-\tau}{2}+\frac{\varepsilon}{2 c}} \geq \pi^{1 *}(\varepsilon, 2) \geq 1-\frac{1-p}{\left(\frac{1-\tau}{2}-\frac{\varepsilon}{2 c}\right) w(\varepsilon, k)} .
$$

For all $k \geq k^{*}(p)$ and for all $\varepsilon \in(0, b-k]$, the difference between the left-hand-side and the right-hand-side of (30) has the same sign as

$$
\frac{(1-\tau) \varepsilon}{2}\left(\frac{2(1-p)}{(1-\tau) c}-\frac{2(b-k)}{4 b k+r}\right)+\frac{\varepsilon}{2 c}(w(\varepsilon, k)-1)+\frac{1-\tau}{2} \frac{\varepsilon^{2}}{4 b k+r},
$$

which is positive. Thus the left-hand-side of (30) is greater than the righthand-side. The right-hand-side of (30) is less than one, and, since by supposition $p>\left(\frac{1+\tau}{2}-\frac{\varepsilon}{2 c}\right) w(\varepsilon, k)$, the left-hand side of (30) is greater than 0 . 
Hence, for all $k \geq k^{*}(p)$ and for all $\varepsilon \in(0, b-k]$, there exists $\pi^{1 *}(\varepsilon, 2) \in[0,1]$ that satisfies (30).

\section{Proof of Proposition 5}

Let $x$ denote the number of endorsements for party 1 . In equilibrium the distribution of $x$ is given the binomial distribution (16) with parameters $n$ and $\hat{\tau}$. We let $x^{*}$ denote the $p$-th quantile of this distribution.

Consider the voting strategy given by

$$
\pi^{1}(\mathbf{y}, \mathbf{e}) \begin{cases}1 & \text { if } x \geq x^{*}+1 \\ d & \text { if } x=x^{*} \\ 0 & \text { if } x \leq x^{*}-1\end{cases}
$$

where the constant $d$ is chosen such that the equilibrium probability of winning is equal to $p$.

Let $\beta^{e_{j}}(\mathbf{y}, \theta)$ be the probability that newspaper $t$ endorses party $e_{t}$ when party 1 deviates to $y_{1}=\theta+k+\varepsilon$ in state $\theta$. Write

$$
\beta^{\mathbf{e}}(\mathbf{y}, \theta)=\beta^{e_{1}}(\mathbf{y}, \theta) \ldots \beta^{e_{n}}(\mathbf{y}, \theta) .
$$

We have

$$
q(\mathbf{y}, \theta)=\sum_{\mathbf{e}} \beta^{\mathbf{e}}(\mathbf{y}, \theta) \pi^{1}(\mathbf{y}, \mathbf{e}) .
$$

Let $\mathbf{e}_{-j}$ be the vector of endorsements with the element $e_{j}$ removed. Define

$$
s_{j}(i) \equiv \sum_{\mathbf{e}_{-j}} \beta^{\left(\mathbf{e}_{-j}, i\right)}(\mathbf{y}, \theta) \pi^{1}\left(\mathbf{y},\left(\mathbf{e}_{-j}, i\right)\right) .
$$

That is, $s_{j}(i)$ is the conditional probability that the median voter chooses party 1 when newspaper $j$ endorses party $i$. We can write the marginal effect of deviation on winning probability as

$$
\left.2 \frac{d q(\mathbf{y}, \theta)}{d \varepsilon}\right|_{\varepsilon=0}=\sum_{j=1}^{n} \frac{1}{c}\left(s_{j}(1)-s_{j}(2)\right) .
$$

Equation (32) expresses the marginal effect as a sum of $n$ terms, each of which represents the effect of an individual newspaper.

Given the voting strategy (31), the influence of a newspaper $j$ can be written as

$$
\begin{aligned}
s_{j}(1)-s_{j}(2) & =f\left(n-1, x^{*}-1\right) d+f\left(n-1, x^{*}\right)(1-d) \\
& =(d-\hat{\tau}) \frac{f\left(n, x^{*}\right)}{\sqrt{n \hat{\tau}(1-\hat{\tau})}} \frac{x^{*}-n \hat{\tau}}{\sqrt{n \hat{\tau}(1-\hat{\tau})}}+f\left(n, x^{*}\right) .
\end{aligned}
$$


Since the distribution of the standardized binomial variable

$$
x^{\prime}=\left(x^{\prime}-n \hat{\tau}\right) / \sqrt{n \hat{\tau}(1-\hat{\tau})}
$$

tends to the unit normal distribution as $n$ tends to infinity, $\left(x^{*}-n \hat{\tau}\right) / \sqrt{n}$ tends to a finite limit of $\Phi^{-1}(p)$ as $n$ tends to infinity (where $\Phi$ is the standard normal distribution function). Furthermore, since $f\left(n, x^{*}\right)$ tends to $1 / \sqrt{2 \pi n \hat{\tau}(1-\hat{\tau})}$, the first term of (33) approaches 0 at the rate $1 / n$, whereas the second term approaches 0 at the rate $1 / \sqrt{n}$. Thus the expression in (32) approaches infinity at the rate $\sqrt{n}$. For $n$ large, we must have

$$
\frac{2(b-k)}{4 b k+r} \leq\left. 2 \frac{d q(\mathbf{y}, \theta)}{d \varepsilon}\right|_{\varepsilon=0}
$$

Hence, $k=0$ can be an equilibrium. 


\section{References}

[1] Alesina, A. (1988) "Credibility and Policy Convergence in a Two-Party System with Rational Voters." American Economic Review, 78, 796805 .

[2] Anderson, S.P.; and McLaren, J. (2007) "Media Mergers and Media Bias with Rational Consumers." Working paper, University of Virginia.

[3] Ansolabehere, S.; Lessem, R.; and Snyder, J.M. (2006) "The Orientation of Newspaper Endorsements in U.S. Elections, 1940-2002." Quarterly Journal of Political Science, 1, 393-404.

[4] Baron, D.P. (2006) "Persistent Media Bias." Journal of Public Economics, 90, 1-36.

[5] Battaglini, M. (2002) "Multiple Referrals and Multidimensional Cheap Talk." Econometrica, 70, 1379-1401.

[6] Bernhardt, D.; Krasa, S.; and Polborn M. (forthcoming) "Political Polarization and the Electoral Effects of Media Bias." Journal of Public Economics.

[7] Besley, T.; and Prat, A. (2006) "Handcuffs for the Grabbing Hand? Media Capture and Government Accountability." American Economic Review, 96, 720-736.

[8] Chan, J.; and Suen, W. (2008) "A Spatial Theory of News Consumption and Electoral Competition." Review of Economic Studies, 75, 699-728.

[9] Dziuda, W. (2007) "Strategic Argumentation." Working paper, Kellogg School of Management.

[10] Feller, W. (1950) An Introduction to Probability Theory and Its Applications, Vol. 1. New York: Wiley.

[11] Fallows, J. (1996) Breaking the News: How the Media Undermine American Democracy. New York: Pantheon Books.

[12] Gans, J.S.; and Smart, M. (1996) "Majority Voting with SingleCrossing Preferences." Journal of Public Economics, 59, 219-237.

[13] Gentzkow, M.; and Shapiro, J. (2006) "Media Bias and Reputation." Journal of Political Economy, 114, 280-316. 
[14] Gilligan, T.W.; and Krehbiel, K. (1987) "Collective Decision-Making and Standing Committees: An Informational Rationale for Restrictive Amendment Procedures." Journal of Law, Economics, and Organization, 3, 287-335.

[15] Gilligan, T.W.; and Krehbiel, K. (1989) "Asymmetric Information and Legislative Rules with a Heterogeneous Committee." American Journal of Political Science, 33, 459-490.

[16] Kahn, K.F.; and Kenney, P.J. (2002) "The Slant of the News: How Editorial Endorsements Influence Campaign Coverage and Citizens' Views of Candidates." American Political Science Review, 96, 381-394.

[17] Kreps, D.M.; and Wilson, R. (1982) "Sequential Equilibrium." Econometrica, 50, 863-894.

[18] Krishna, V.; and Morgan, J. (2001a) "A Model of Expertise." Quarterly Journal of Economics, 116, 747-775.

[19] Krishna, V.; and Morgan, J. (2001b) "Asymmetric Information and Legislative Rules: Some Amendments." American Political Science Review, 95, 435-452.

[20] Larcinese, V.; Puglisi, R.; and Snyder, J.M. (2007) "Partisan Bias in Economic News: Evidence on the Agenda-Setting Behavior of U.S. Newspapers." National Bureau of Economic Research Working Paper, No. 13378.

[21] Martinelli, C. (2001) "Elections with Privately Informed Parties and Voters." Public Choice, 108, 147-167.

[22] Massing, M. (2005) "The Press: The Enemy Within." The New York Review of Books. Vol. 52, Number 20.

[23] Milgrom, P.; and Roberts, J. (1986), "Relying on the Information of Interested Parties." RAND Journal of Economics, 17, 18-32.

[24] Mullainathan, S.; and Shleifer, A. (2005) "The Market for News." American Economic Review, 95, 1031-1053.

[25] News Audiences Increasingly Politicized, The Pew Research Center for the People and the Press, 2004. 
[26] Puglisi, R. (2007) "The Spin Doctor Meets the Rational Voter: Electoral Competition when Mass Media have Agenda-Setting Effects." Working paper, Massachusetts Institute of Technology.

[27] Schultz, C. (1996) "Polarization and Inefficient Policies." Review of Economic Studies, 63, 331-344.

[28] Stromberg, D. (2004) "Mass Media Competition, Political Competition, and Public Policy." Review of Economic Studies, 71, 265-284. 